\title{
OPEN SOURCE LOW-COST APPROACH TO TERRAIN MAPPING USING DRONE WITH LIDAR
}

\author{
Adnan Masic, Boran Pikula, Dzevad Bibic \& Faruk Razic
}
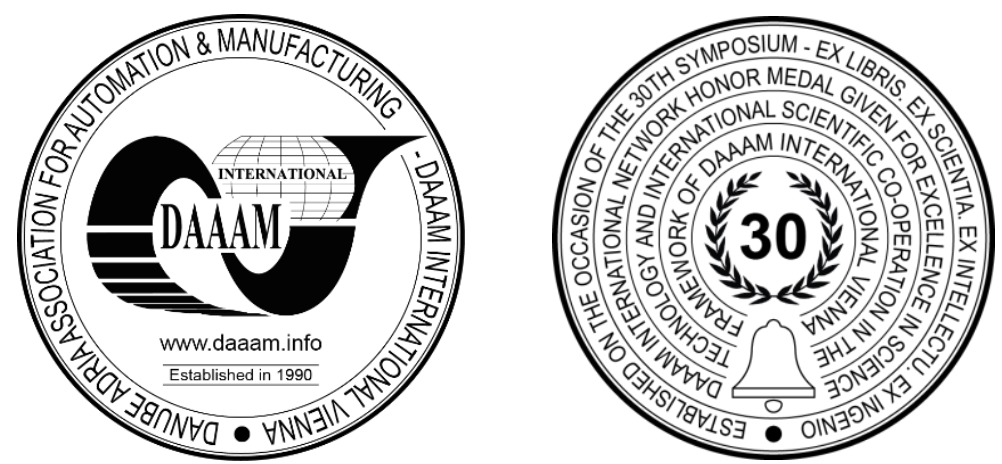

This Publication has to be referred as: Masic, A[dnan]; Pikula, B[oran]; Bibic, D[zevad] \& Razic, F[aruk] (2021). Open Source Low-cost Approach to Terrain Mapping Using Drone with LiDAR, Proceedings of the 32nd DAAAM International Symposium, pp.0117-0122, B. Katalinic (Ed.), Published by DAAAM International, ISBN 978-3-90273433-4, ISSN 1726-9679, Vienna, Austria

DOI: $10.2507 / 32$ nd.daaam.proceedings.017

\begin{abstract}
A novel method for terrain mapping is presented in this paper. It is based on low-cost open source components, which brings this innovative technique to a much wider group of researchers than ever before. The in-house developed drone was used together with a commercially available LiDAR sensor to produce a terrain mapping platform. This system was tested in two field locations with good results. In some aspects of performance, the drone surpassed commercially available solutions that are much more expensive and closed.
\end{abstract}

Keywords: LiDAR; drone; terrain mapping; inertial measurement unit; global navigation satellite system.

\section{Introduction}

In the context of the development of automation and robotics, the use of LiDAR (light detection and ranging) is an increasingly popular technological trend. For example, the use of LiDAR in the fields of autonomous vehicles, aerial surveying, power line inspections, forest research, etc. is being intensively investigated. There are numerous examples of papers in the literature. Hopkinson investigated laser pulse return intensity and canopy frequency distribution [1], while Wulder analyzed LiDAR plots [2]. Lipovsky used LiDAR to study rock and ice avalanches [3], and Hopkinson [4] assessed the influence of glacier downwasting on water resources. Marselis evaluated the potential of full-waveform LiDAR for mapping pan-tropical tree species richness [5]. Kettridge used airborne LiDAR in [6]. Chasmer investigated laser pulse penetration through a conifer canopy by integrating airborne and terrestrial LiDAR [7]. Yeong highlighted some of the challenges in sensor fusion technology (including LiDAR) in autonomous vehicles [8]. Tang analyzed the LiDAR sensor performance on detecting pedestrians under different weather conditions [9]. Chen performed research on control and dynamic property of autonomous vehicle adaptive LiDAR system [10]. Elhousni surveyed 3D LiDAR localization for autonomous vehicles [11].

However, what is common to all these references is the use of sophisticated and expensive equipment, which is generally inaccessible to researchers who do not have a large budget. In the case of aerial measurements, costs increase further due to the need to use an aircraft capable of carrying sophisticated (and relatively heavy) measuring equipment. The goal of our work is to develop an open and accessible drone-based platform, the price of which is one or two orders of magnitude lower than commercially available solutions. 


\section{The drone-based platform}

Unmanned aerial vehicles (drones) are used for a variety of purposes, including data acquisition [12], temperature inversion measurements [13], particulate matter (PM) concentration measurements [14], and simultaneous measurements of temperature and PM concentration above urban area [15]. Our drone platform was developed in-house, based on Ardupilot open-source autopilot and commercially available electronic components [16]. This platform has a modular design and can carry various sensors and equipment, including electrochemical sensors for toxic gases [17], [18], and the abovementioned PM sensors. In our previous work we discussed quality assurance (QA) procedures that were applied to ensure reliable data [19], [20]. For this research, LiDAR with 100 meters range, LW20/C (LightWare, USA) was configured and installed on the drone (Figure 1). For terrain mapping the measurements from LiDAR are not sufficient for the calculation of terrain height, because the drone moves during the flight. Thus, it is necessary to combine raw readings from the LiDAR with the drone Attitude and Heading Reference System (AHRS) to calculate terrain height at given geographical coordinates. During the flight of the drone, which is in our case limited to 30 minutes, a discrete set of points is obtained. Spatial interpolation methods were employed afterward, using our previously explained methodology [21].

The following steps are performed to calculate terrain height:

1. Choose an area to survey and create an automatic mission for the drone.

2. Execute mission and record data from both lidar and drone AHRS.

3. Calculate terrain height in the geographic coordinate system.

4. Based on the density of measured points, create a grid for interpolation and calculate interpolated values at cell centers. In this research Inverse distance weighting (IDW) and Kriging algorithm were used for interpolation.

5. Plot 3D surface map of the terrain.

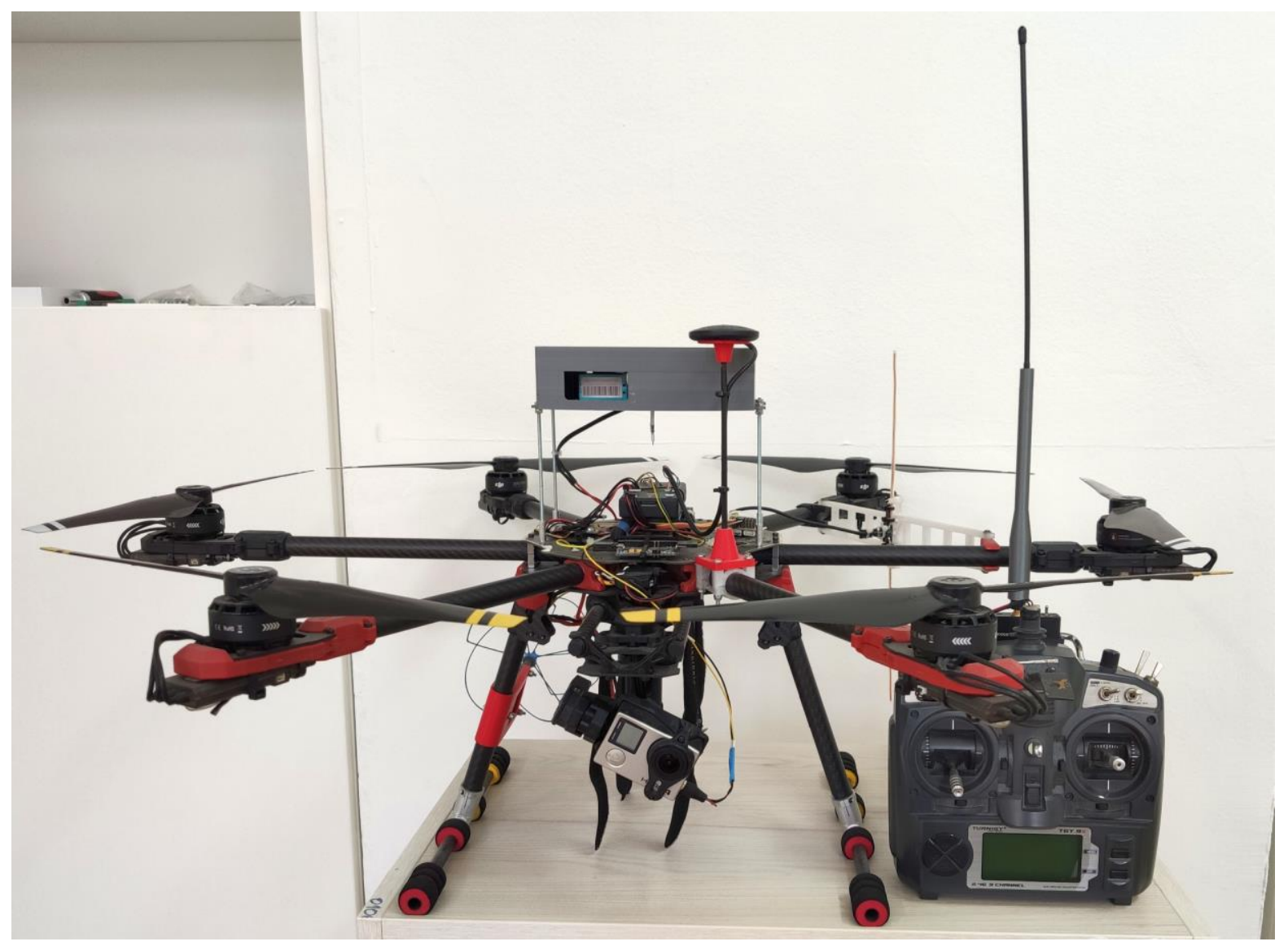

Fig. 1. The in-house developed drone based on open-source flight controller.

\section{Field Tests}

Two field tests in Sarajevo Canton were selected for this research (Figure 2): Trebević mountain (test 1) and Nišići plateau (test 2). In test 1 we have surveyed an area of $113531 \mathrm{~m}^{2}$ to map the terrain which has a complex topology (Figure 3 ). The second test was the measurement of elevation profile over $1.5 \mathrm{~km}$ long line and to compare that profile with available data from Google Earth. 


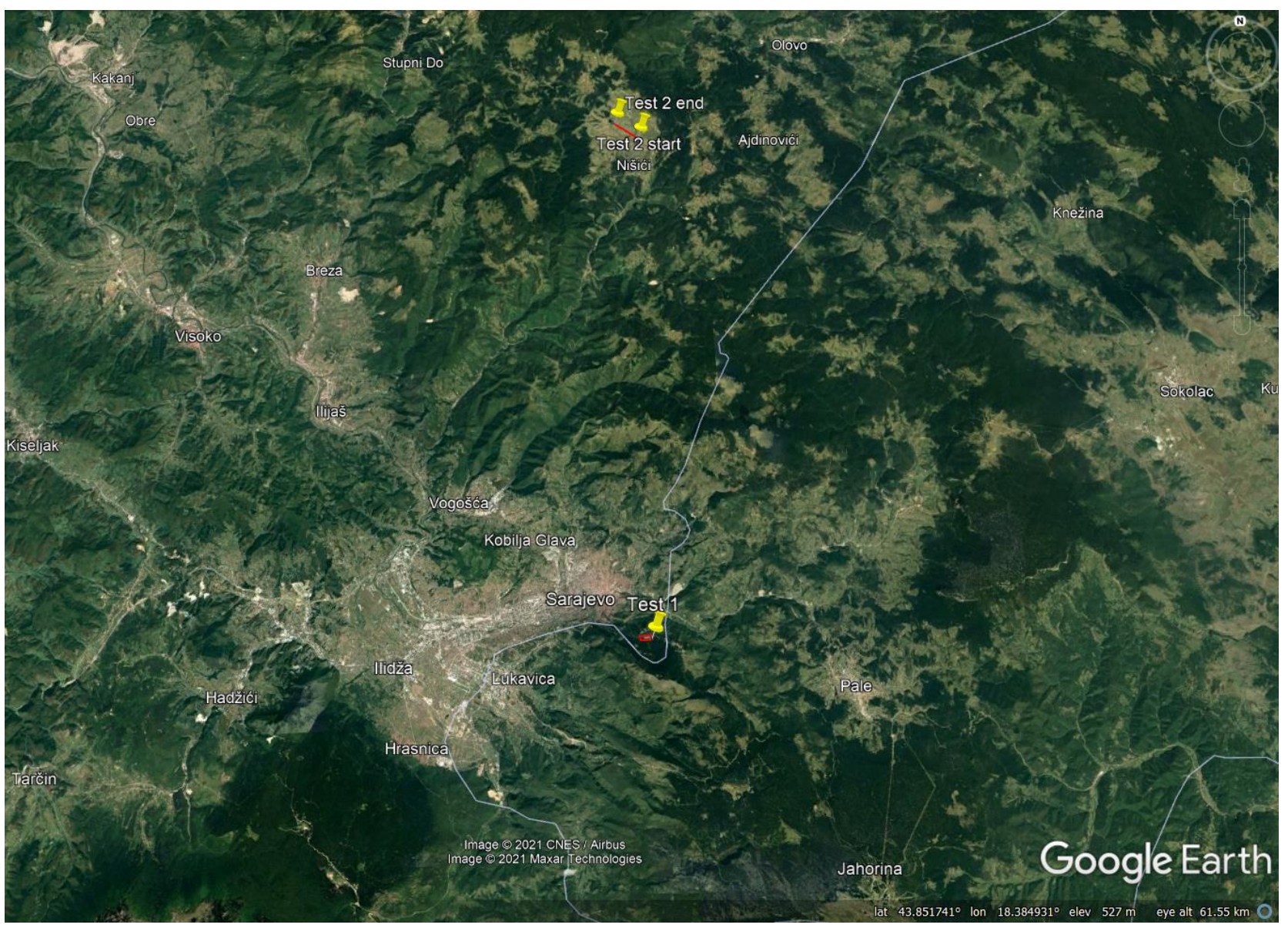

Fig. 2. Test locations.
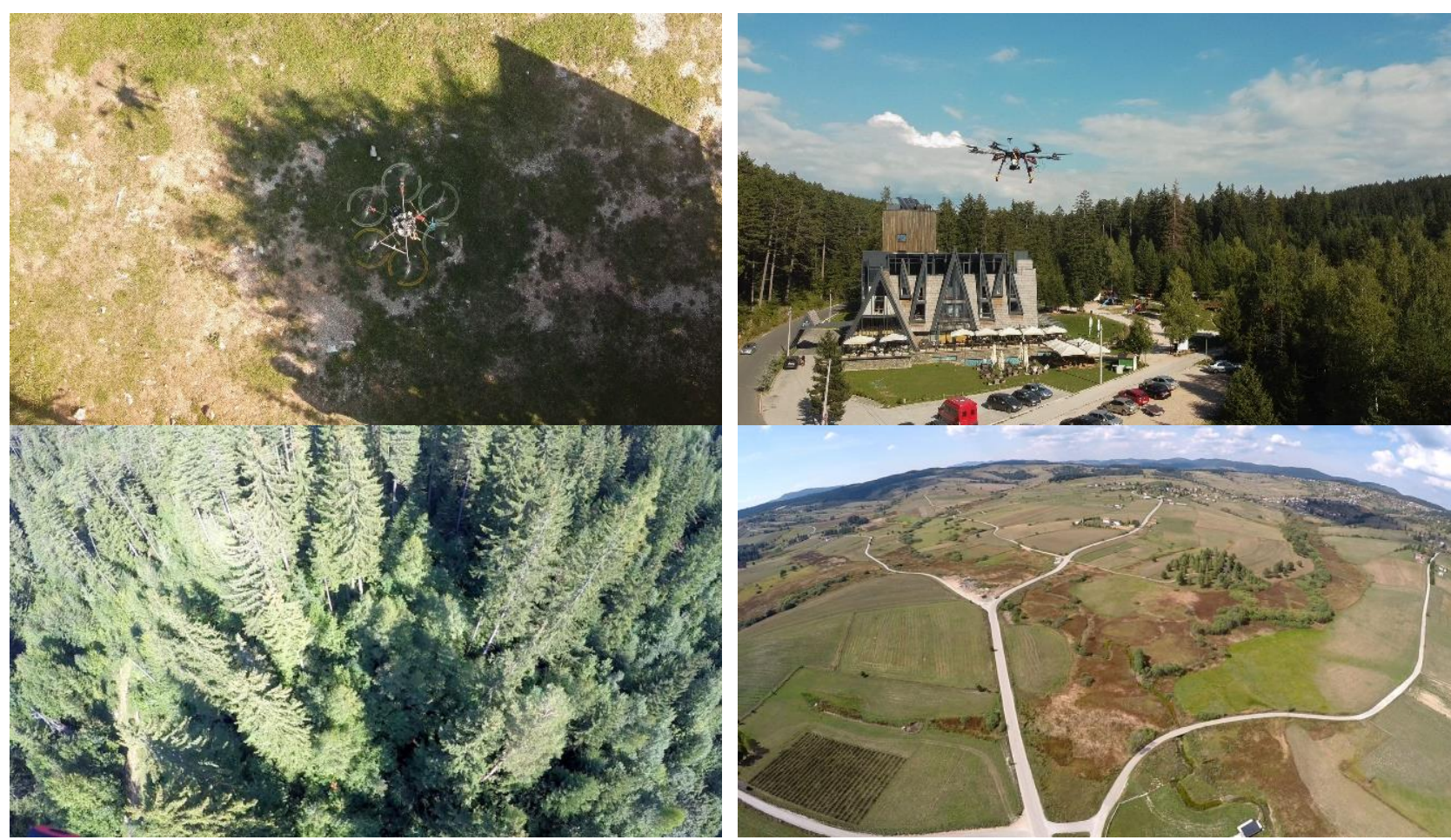

Fig. 3. Clockwise from top left: image of the flying drone taken from above, mapping of terrain with buildings, forest mapping, and elevation profile measurement. 


\section{Results}

Figure 3 shows the terrain model computed using the 5 steps explained in section 2. During the drone flight we have collected 23987 individual LiDAR measured points, over an area of $113531 \mathrm{~m}^{2}$, which gives the point density of 0.211 points per $\mathrm{m}^{2}$. We would like to note that the aim of this research is proof of concept, rather than high point density (which will be increased in future work). For IDW calculations power exponent 2 was used.
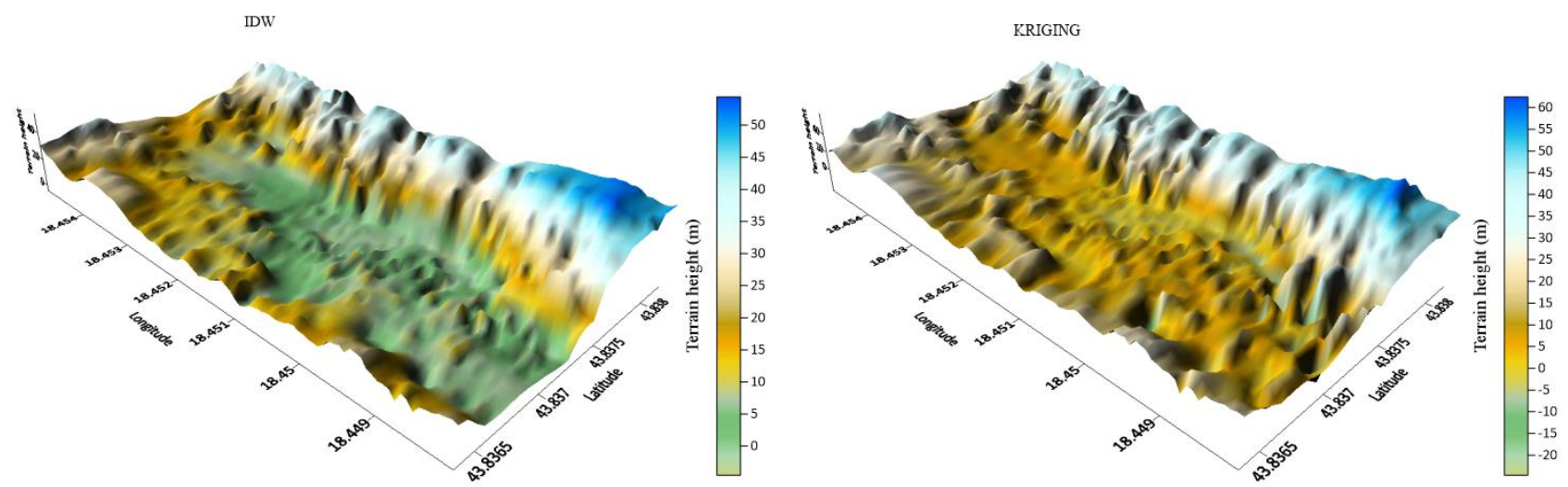

Fig. 4. Terrain height was calculated using IDW and Kriging algorithm.

Elevation profile measurement (Figure 5) was straightforward, giving the interesting result: the profile is very similar to one obtained from Google Earth, but it gives more details and is generally more accurate.

\section{LiDAR measurement of elevation profile}
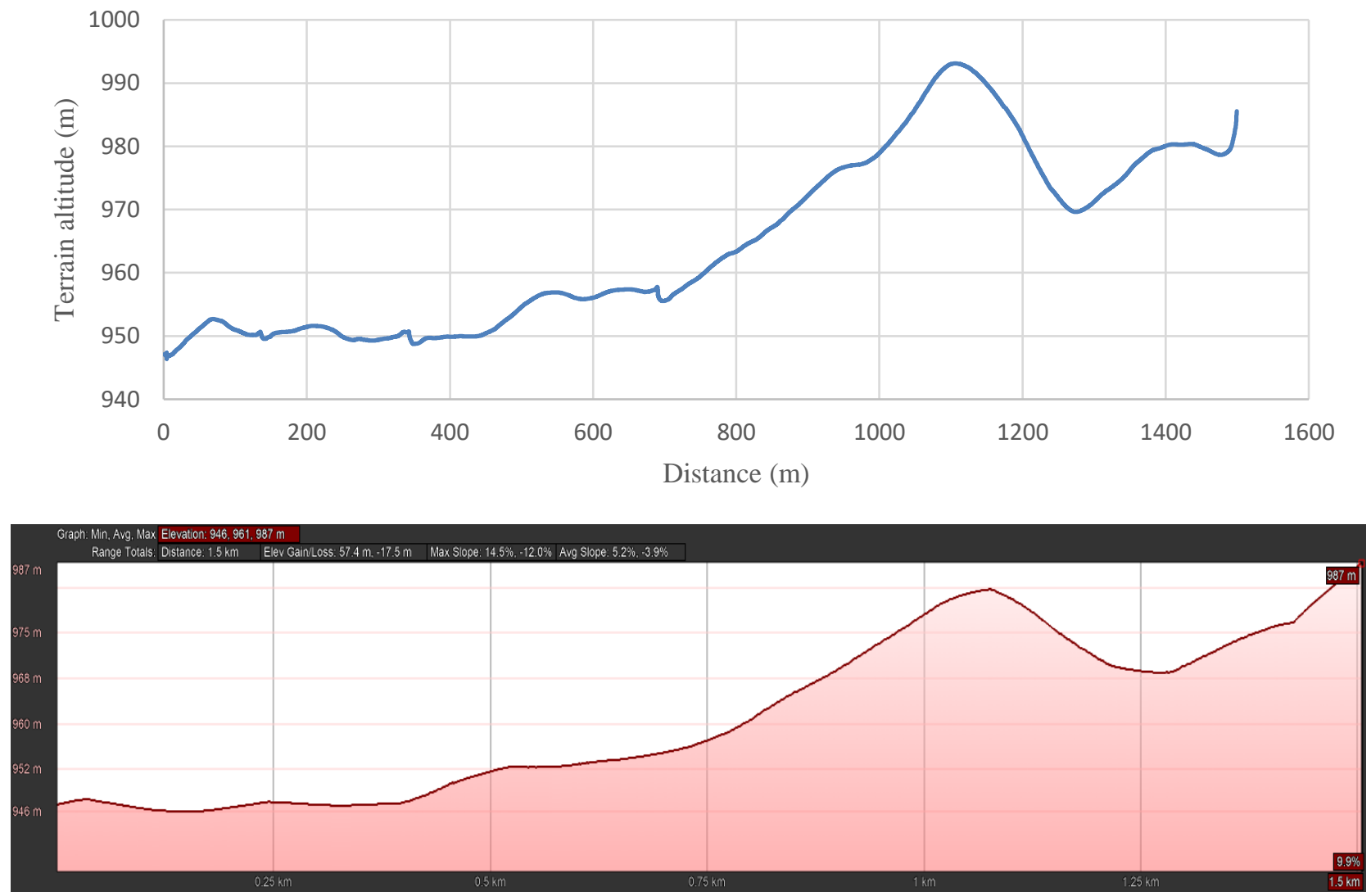

Fig. 5. Elevation profile at Nišići. Top: actual measurement, bottom: screenshot from Google Earth profile of the same terrain.

These results show that terrain mapping and elevation profile measurement are suitable test cases for the proposed concept of a low-cost aerial LiDAR platform. Autonomous flight mode was used with the predefined mission, so the measurements could be repeated if necessary. 


\section{Conclusion}

The concept of a low-cost and open-source drone platform with LiDAR for terrain mapping was successfully demonstrated using two field tests. The survey area of $113531 \mathrm{~m}^{2}$ at Trebević mountain was covered in single drone flight and terrain height was calculated using IDW and Kriging algorithm. The second test produced an $1.5 \mathrm{~km}$ long elevation profile at Nišići plateau, which agrees well with Google Earth profile but gives more details.

The first results are a positive and encouraging step towards massive adoption of this advanced technology in scientific research. In future work we will increase the capabilities of our platform, including the design and construction of a more powerful drone, installation of a more capable LiDAR sensor, and better data acquisition system to open new possibilities for low-cost drone investigations. These may include: high-resolution terrain mapping, research of forest, mapping of buildings and wider urban area, etc.

\section{References}

[1] Hopkinson, C. (2007). The influence of flying altitude, beam divergence, and pulse repetition frequency on laser pulse return intensity and canopy frequency distribution, Canadian Journal of Remote Sensing, 33:4, 312-324, DOI: $10.5589 / \mathrm{m} 07-029$

[2] Wulder, M. A.; White, J. C.; Bater, C. W.; Coops, N. C.; Hopkinson, C. \& Chen, G. (2012). Lidar plots - a new large-area data collection option: context, concepts, and case study, Canadian Journal of Remote Sensing, 38:5, 600618, DOI: $10.5589 / \mathrm{m} 12-049$

[3] Lipovsky, P. S.; Evans, S. G.; Clague, J. J. et al. (2008). The July 2007 rock and ice avalanches at Mount Steele, St. Elias Mountains, Yukon, Canada. Landslides 5, 445-455 (2008). DOI: 10.1007/s10346-008-0133-4

[4] Hopkinson, C. \& Demuth, M. N. (2006). Using airborne lidar to assess the influence of glacier downwasting on water resources in the Canadian Rocky Mountains, Canadian Journal of Remote Sensing, 32:2, 212-222, DOI: $10.5589 / \mathrm{m} 06-012$

[5] Marselis, S. M.; Abernethy, K.; Alonso, A. et al. (2020). Evaluating the potential of full-waveform lidar for mapping pan-tropical tree species richness. Global Ecol Biogeogr. 2020; 29: 1799- 1816. DOI: 10.1111/geb.13158

[6] Kettridge, N.; Lukenbach, M. C.; Hokanson, K. J.; Hopkinson, C.; Devito, K. J.; Petrone, R. M.; Mendoza, C. A. \& Waddington, J. M. (2017). Low evapotranspiration enhances the resilience of peatland carbon stocks to fire. Geophysical Research Letters, 44, 9341- 9349. DOI: 10.1002/2017GL074186

[7] Chasmer, L.; Hopkinson, C. \& Treitz, P. (2006). Investigating laser pulse penetration through a conifer canopy by integrating airborne and terrestrial lidar, Canadian Journal of Remote Sensing, 32:2, 116-125, DOI: 10.5589/m06011

[8] Yeong, D. J.; Velasco-Hernandez, G.; Barry, J. \& Walsh, J. (2021). Sensor and Sensor Fusion Technology in Autonomous Vehicles: A Review. Sensors 2021, 21, 2140. DOI: 10.3390/s21062140

[9] Tang, L.; Shi, Y.; He, Q.; Sadek, A. W. \& Qiao, C. (2020). Performance Test of Autonomous Vehicle Lidar Sensors Under Different Weather Conditions. Transportation Research Record. 2674(1):319-329. DOI: $10.1177 / 0361198120901681$

[10] Chen, J.; Zhang, H.; Lu, Y. \& Zhang, Q. (2020). The Research on Control and Dynamic Property of Autonomous Vehicle Adaptive Lidar System, 2020 International Conferences on Internet of Things (iThings) and IEEE Green Computing and Communications (GreenCom) and IEEE Cyber, Physical and Social Computing (CPSCom) and IEEE Smart Data (SmartData) and IEEE Congress on Cybermatics (Cybermatics), 2020, pp. 462-468, DOI: 10.1109/iThings-GreenCom-CPSCom-SmartData-Cybermatics50389.2020.00086.

[11] Elhousni, M. \& Huang, X. (2020). A Survey on 3D LiDAR Localization for Autonomous Vehicles, 2020 IEEE Intelligent Vehicles Symposium (IV), 2020, pp. 1879-1884, DOI: 10.1109/IV47402.2020.9304812.

[12] Masic, A. (2015). Unmanned Aerial Vehicle as Data Acquisition System. Journal of Trends in the Development of Machinery and Associated Technology. Vol. 19, No. 1, 2015, ISSN 2303-4009 (online), p.p. 181-184.

[13] Masic, A.; Musemic, R. \& Dzaferovic-Masic, E. (2016). Temperature Inversion Measurements in Sarajevo Valley Using Unmanned Aerial Vehicles, Proceedings of the 27th DAAAM International Symposium, pp.0423-0427, B. Katalinic (Ed.), Published by DAAAM International, ISBN 978-3-902734-08-2, ISSN 1726-9679, Vienna, Austria, DOI: $10.2507 / 27$ th.daaam.proceedings.062

[14] Masic, A.; Pikula, B. \& Bibic, D. (2017). Mobile Measurements of Particulate Matter Concentrations in Urban Area, Proceedings of the 28th DAAAM International Symposium, pp.0452-0456, B. Katalinic (Ed.), Published by DAAAM International, ISBN 978-3-902734-11-2, ISSN 1726-9679, Vienna, Austria DOI: 10.2507/28th.daaam.proceedings.063

[15] Masic. A.; Bibic, D.; Pikula, B.; Dzaferovic-Masic, E. \& Musemic, R. (2019). Experimental study of temperature inversions above urban area using unmanned aerial vehicle. Thermal Science, Vol. 23, No. 6A, pp. 3327-3338, DOI: 10.2298/TSCI180227250M

[16] Saric I.; Masic A. \& Delic, M. (2021). Hexacopter Design and Analysis. In: Karabegović I. (eds) New Technologies, Development and Application IV. NT 2021. Lecture Notes in Networks and Systems, vol 233. Springer, Cham. DOI: 10.1007/978-3-030-75275-0_9 
[17] Masic, A.; Bibic, D.; Pikula, B. \& Razic, F. (2018). New approach of measuring toxic gases concentrations: principle of operation, Proceedings of the 29th DAAAM International Symposium, pp.0882-0887, B. Katalinic (Ed.), Published by DAAAM International, ISBN 978-3-902734-20-4, ISSN 1726-9679, Vienna, Austria, DOI: 10.2507/29th.daaam.proceedings.127

[18] Bibic, D.; Pikula, B.; Masic, A. \& Razic, F. (2018). New approach of measuring toxic gases concentrations: application examples, Proceedings of the 29th DAAAM International Symposium, pp.0876-0881, B. Katalinic (Ed.), Published by DAAAM International, ISBN 978-3-902734-20-4, ISSN 1726-9679, Vienna, Austria, DOI: 10.2507/29th.daaam.proceedings.126

[19] Masic, A.; Bibic, D. \& Pikula, B. (2019). On the applicability of low-cost sensors for measurements of aerosol concentrations, Proceedings of the 30th DAAAM International Symposium, pp.0452-0456, B. Katalinic (Ed.), Published by DAAAM International, ISBN 978-3-902734-22-8, ISSN 1726-9679, Vienna, Austria DOI: 10.2507/30th.daaam.proceedings.060

[20] Masic, A.; Pikula, B.; Bibic, D.; Musemic, R. \& Halac, A. (2018). Calibration and Assessment of Low-cost Dust sensors, Proceedings of the 29th DAAAM International Symposium, pp. 523-528, B. Katalinic (Ed.), Published by DAAAM International, ISBN 978-3-902734-xX-X, ISSN 1726-9679, Vienna, Austria, DOI: 10.2507/29th.daaam.proceedings.075

[21] Masic, A.; Bibic, D.; Pikula, B.; Dzaferovic-Masic, E. \& Razic, F. (2018). Visualization of Data from Network of Sensors: Appropriate Spatial Interpolation Method, Proceedings of the 29th DAAAM International Symposium, pp.0529-0533, B. Katalinic (Ed.), Published by DAAAM International, ISBN 978-3-902734-20-4, ISSN 1726-9679, Vienna, Austria DOI: 10.2507/29th.daaam.proceedings.076 